\title{
Science communication as a preventative tool in the COVID19 pandemic
}

Gagan Matta (1) ${ }^{1 \times}$

Humans have witnessed epidemics and pandemics periodically throughout history. Often, such infectious outbreaks have resulted in entire civilisations struggling against possible extinction. Despite recent clinical advancements and technological developments, issues of neglected sustainability and lax health hygiene practices, among others, have provided a context for the emergence of the COVID19 pandemic. Against such a backdrop, scientific communication using diversified tools could play a significant role in efforts towards preparedness and control, as well as the initiation of immediate remedial measures in the fight against epidemics and pandemics. These tools could help to increase understanding of the scientific solutions to minimise the outbreaks of infectious diseases, thereby strengthening societal immunity. This paper considers the history of epidemics/pandemics to draw attention to their occurrence, effects and potential impacts on human societies. In addition, it defines the major factors underpinning the various infectious outbreaks over the last three decades. Constructive preparation and preventative stages for authorities, scientists and researchers to check and diminish the impact of epidemics and pandemics during and postoutbreak are suggested while focusing on the need for science communication in the healthcare system. The paper also reviews recent empirical studies and WHO guidelines. Communication through appropriate communicators may help cut through the noise, share facts and boost confidence in science and governance. The impact of science communication on the interplay between government-expert-public or society could help promote positive behavioural change as well as overcome linguistic barriers. 


\section{Introduction}

he scientific community has forecast global pandemic threats by considering current overpopulation, everincreasing pollution and historical clues; and warned several times to governments for such threats (The Guardian 2020). The historical shreds of the earth also indicated the existence of several deadly diseases in the foregone human population, but the overall spread of such diseases was limited due to the scattered human settlements and pollution-free ambience. Around 10,000 years ago, the human settlement was started in the form of distant civilisations and societies. The unique characteristics of these settlements were domestication of animals and practising agriculture (Gupta 2004). Along with the several advantages, the evolution of the societal system, it also posed the risk of infectious diseases due to poor hygiene and sensation conditions within the human settlement or society. Living in a societal system, often in overcrowded, probably favoured many pathogens for species jump, which caused many severe infections and diseases to human beings (Lindahl and Grace 2015). The oldest known epidemic that was occurred at 3000 B.C., called Circa, wiped the entire prehistoric villages of China (Jarus 2020). The historical pieces of evidence reveal that no age group were spared due to quick occurrence of pandemic without giving time even for proper burials, led to collective scorching.

Historical insight of pandemics. In 430 B.C., another epidemical outbreak smallpox reported that is caused by the Variola virus, transmitted from dermal contact and has the capability of air dispersal. This outbreak reduced the total population of Greece with up to $20 \%$. The Greek historian Thucydides (460-400 B.C.) narrated in his book as "individuals suffered extreme heat in the head, irritation in the eyes, inner parts of the face becoming bloody, emitting an unnatural and fetid breath" (translated by Richard Crawley from the book "The History of the Peloponnesian War," London Dent, 1914).

Soldiers unintentionally brought epidemic Antonine Plague (expected to be smallpox) in spoils of victory, killed five million individuals in the entire Roman Empire 165-180 A.D., (April Pudsey, Roman History at Manchester Metropolitan University, in the book "Disability in Antiquity," Routledge, 2017). Some historians believed that combatants returned as carriers of infection after the battle against Parthia, affecting from 27 B.C. to 180 A.D. In 541 A.D. Plague of Justinian dispersed through rats and infected fleas while killing 50 million people in over 200 years in Asia, the Middle East and Mediterranean regions.

During 1346-1353 A.D., the Black Death pandemic, also known as the greatest catastrophe ever, travelled from Asia to Europe, killed around 50\% of Europe population by strains of the bacterium Yersinia pestis. In 1545-1548 A.D., the Cocoliztli epidemic occurred as viral haemorrhagic fever killing 15 million individuals in Mexico and Central regions of America.

Epidemic smallpox in 1519, A.D. killed 8 million of 25 million native populations in 2 years, of now called Mexico. In the next century, only 2 million inhabitants remained uninfected rest severely suffered by the number of infectious diseases transmitted by various European Explorers. The outbreak was on America's native population, and the impact was still not over, killed almost 20 million individuals. In 1633 A.D. Smallpox was brought by various migrants from the Netherlands, France, and Great Britain to Massachusetts.

Last two centuries faced a rise in epidemics with an increase in population, pollution, transportation, industrialisation and urbanisation. Since 1860 A.D. Modern Plague (Century's most severe epidemic) killed more than twelve million people in India, China and Hong Kong during the next three decades and controlled after the development of medicine.

During 1889-1890 A.D., epidemic Flu outbreak occurred, in St. Petersburg before spreading in Europe and the rest of the world, despite that when the air travel did not exist. Another event Plague happened in 1910-1911 A.D. in Manchuria killed 60,000 people, counted the largest plague outbreak of the 20th Century. Till today it occasionally occurs in parts of sub-Saharan Africa.

Pandemic Great Spanish Flu, the most significant pandemic of the last Century, through 1918-1919 A.D., killed approximately 500 million people across the globe, with one-fifth of the population belonging to some indigenous communities which were at the edge of extinction. It had a significant impact on the soldiers of World War I. Epidemic Polio, a contagious disease appeared in summer season and was at peak during the 1950s in the USA, affected 60,000 children and killed more than 3000 individuals until the development of vaccination in 1954 A.D. Within 1957-1958 A.D., the pandemic Asian Flu identified, having its roots in China, took the lives of 1 million people. The virus was a combination of different avian flu which had an outbreak in Singapore, Hong Kong and in the coastal areas of the USA.

In 1984 A.D., the virus was identified as Human immunodeficiency virus (HIV) by scientists termed causing AIDS, killed more than 5000 individuals in the USA during the same year. Since the first case identified, approximately 25 million individuals lost their lives, while today, more than 35 million individuals infected across the globe. Along with vaccination and precautions, awareness was one such element to minimise the cases of AIDS. After many decades, the HIV infection does not have a significant cure, although some treatment processes were developed in the 1990s, allowed individuals to live everyday life span with regular medication.

In the last two decades, much rise in outbreaks of endemics and epidemics showing the disastrous effect on various regions across the world. SARS (Severe Acute Respiratory Syndrome) first identified in China in 2003 A.D., reported with 8000 cases and 774 deaths.

2009 A.D., a pandemic Swine Flu was affected with a new strain of H1N1 virus, originated in Mexico before spreading globally. In one year, 1.25 billion individuals infected by the virus and deaths reported were approximately 575,000 . Out of total death ratio, $80 \%$ were below the age of 65 years. Swine flu counted as communicable diseases through respiration of pigs infected by a Type A influenza virus.

Epidemic cholera killed around 10,000 people in Haiti in 2010 A.D., while the entire country was like paralysed due to postearthquake in the same year, increasing the severity of the epidemic in the entire nation. In 2012 A.D., more than 1,22,000 individuals have died across the globe, infected with a massive transmissible infection caused by a virus measles. 2012 A.D. itself, typhoid fever killed around 2,16,000 individuals. Tuberculosis, an infectious bacterial disease killed about 1.3 million individual same years, increased the worries for health officials with several contagious diseases in one year only.

2014 A.D., in West Africa, an epidemic of Ebola virus (haemorrhagic fever) outbreak, took the lives of 11,300 individuals and existed till 2016 A.D. Initially reported in bats in Sudan and Democratic Republic of Congo in 1976 A.D.; still, researchers are struggling to find the specific medication and vaccination for Ebola. In the same year, 2016 A.D., WHO declared the Ebola virus a pandemic over the Zika virus envisaging 3 to 4 million people infected in a year, with its extreme and quick outbreak all over the USA. The virus Zika was 


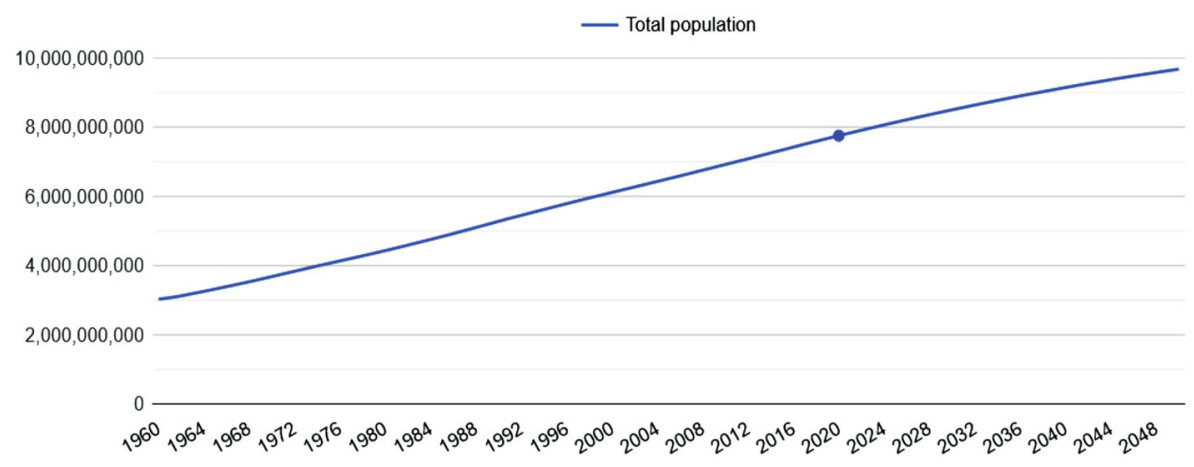

(a)

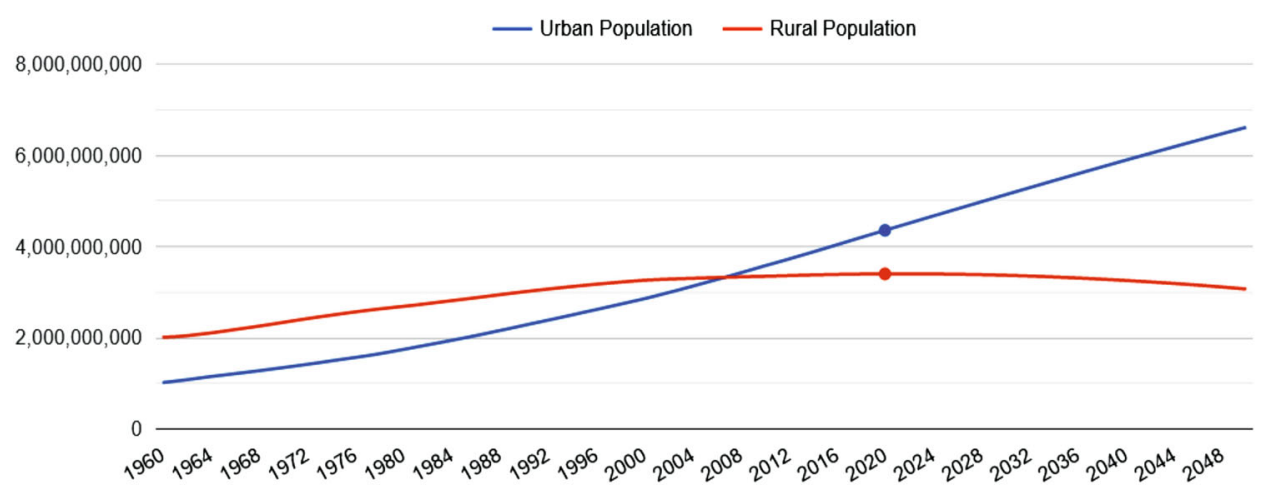

(b)

Fig. 1 Change in global population statistics from 1960 to expected in 2048. Graph showing (a) tremendous increase in total population (b) increase in urbanisation while decline in rural population. Open Source: https://populationstat.com/.

a mosquito-borne infection causing congenital disabilities, microcephaly, miscarriage and neurological deficits.

Various pathogens causing epidemics and pandemics always have resilient foes of humanity. While achieving all the advancements in technologies from space science to development, humans are still struggling to develop vaccinations to prevent many infectious diseases (Wang et al., 2016). However, many viruses do not have severity on a present population like other pandemics but could have a significant impact on forthcoming generations with unsustainable development, climate change and other environmental factors.

Factors behind the emergence of infectious outbreaks in the last three decades. Epidemics and pandemics are infectious diseases, transferred from one species to another, shortening time to extinction or giving revolution signals. Since 3000 B.C., about 8 to 10 epidemics occurred, but in the last two centuries, disastrous events tripled in the number. In recent times, the outbreaks of infectious diseases reported were viz. HIV, Ebola, SARS, in different continents, geographic ranges, with a rapid increase in population and developmental activities. (Fig. 1)

According to the World Health Organization, the number of global health emergencies declared in the last decade only; the latest is in 2020, i.e., pandemic COVID19 and few others outbreaks like epidemic Zika and Ebola. The impact of infectious diseases or viruses do not confine to regions or continents but outburst with the upsurge in destructive efficiency, targeting the individual immune system and spread rapidly, making them carriers. The primary reason for the increase in the severity of infectious diseases is mutation due to changes in environmental conditions like climate change and loads of toxic elements discharged in the atmosphere.
1. The natural environment: The most crucial factor behind the balances of the earth ecosystem, is severely impacted in the last three decades by the greed of humanity. Talking about global health index, always suggested by scientists to act on conservation and preservation of natural environment and resources including climate change. "The Lancet" brings down the world's top environmentalists, arguing the impact of global climate change and the rise in population, threatening, in context of global health, including global emergencies like epidemic and pandemic. In the context of the spread of infection or virus, the most impactful environmental factor is temperature, rising due to climate change and change in global seasonal patterns.

2. Population: According to the United Nations, in 1950, the world population estimated was 2.6 billion, while in 2011, it reached 7 Billion. According to Allen et al. (2008), the parallel correlation between the threat of evolution of pandemics and population density rise is robust. The enormous upsurge in the population increased the numbers of individuals living to reproductive age with medical science and technological developments, urbanisation, migration and majorly change in fertility rate. Studies suggest that by 2050 , the population expected to be 9.7 Billion, while by 2100 , crossing 11 Billion with maximum population residing in urban areas. $61 \%$ of the global population lives in Asia, majorly in China and India, and according to World Population Prospects 2019 (UNDESA 2019), before 2030, India, overtaking China with a tag of the most populous country, while China's population expected to decrease by $2.2 \%$. After Asia, Africa, the fastgrowing continent in terms of the community, it estimated that it would double the population by 2050 due to the 
highest population growth rate among significant areas. Europe, it is estimated that in 55 countries, a decrease in population by 2050 , even in some expected to decrease by $10-15 \%$. As stated by the UNDESA (2003), the Fertility level in a European country is lesser than the actual number of individuals (approx. 2.1 children per woman) for complete replacement of the population; in the long run, the fertility level for replacement in last for several decades. World Population Prospects (2019, Revision) estimated the fertility rate is falling from 2.5 in 2019 to 2.2 by 2050 children per woman, but the population increases life longevity from 72.6 years in 2019 to an expected 77.1 years in 2050 of every individual. But it depends on developed and developing countries, providing facilities and infrastructure according to sustainable development. The World Health Organization's Global Health Observatory (GHO) Database shows that people living in urban areas in 2014 are in total $54 \%$ of the entire world population continually growing while compared with 1960, 34\%. Estimates suggest that by 2030 approximately $1.5 \%$ of the urban population is rising globally. While in the context of the records mentioned above, specific data in table and graphical forms are collected represented from (Tables 1-4 and See Fig. 2).

3. Urbanisation: The unplanned development of civilised society, is another big reason for the quick outbreak of various diseases and infections. Close packed colonies with the dense population having no space for fresh air can quickly impact severely, converting endemic into an epidemic. Civilised settlements called cities, with more than half of the world population with rest, wanting to follow the same, are running to face "an emerging humanitarian disaster" while counting breeding grounds for infections and virus's outbreak. Migration of rural communities along with cattle are seen in the last three decades for animal food products supplies, increase the risk to leap across species. According to Ali Khan, the former director in the office of Public Health Preparedness and Response at the Centre for Disease Control and Prevention CDC, mentioned in the book "The Next Pandemic" "many infections coming out from Asia and Africa are having a vital link between the environment, humans beings and animals (Hanage, 2017).

4. Health hygiene: Clean water, sanitation and health hygiene are the basic need with food and shelter, for which many regions of the world are still struggling, causing weak impunity and immunity. The severity of even a small infection or virus is very high to the individuals with the low immune system, can quickly be poorly impacted during any endemic or pandemic. In 2014-2015, Ebola epidemic outbreak in different parts of America and West Africa with the survival of every infected American individual whereas approximately 11,000 killed in West Africa. Specific measures were taken in different parts of the African continent by the World Health Organization, but with poverty and lack of WASH facilities, weak immune system and lack of vaccinations, preparedness and prevention were not justified.

5. Travel and trade: Till the 19th Century, mode of travel, trade and connectivity was through roads and sea routes with slave trading in the 16th and 17th centuries and rats in food storage sections, accelerated the spread of various infectious diseases or viruses causing pandemic across the world. In the last Century, improvisation in the transportation system and connectivity, frequency of infectious diseases outbreak has increased while crossing the continental barriers. With significant transformations in

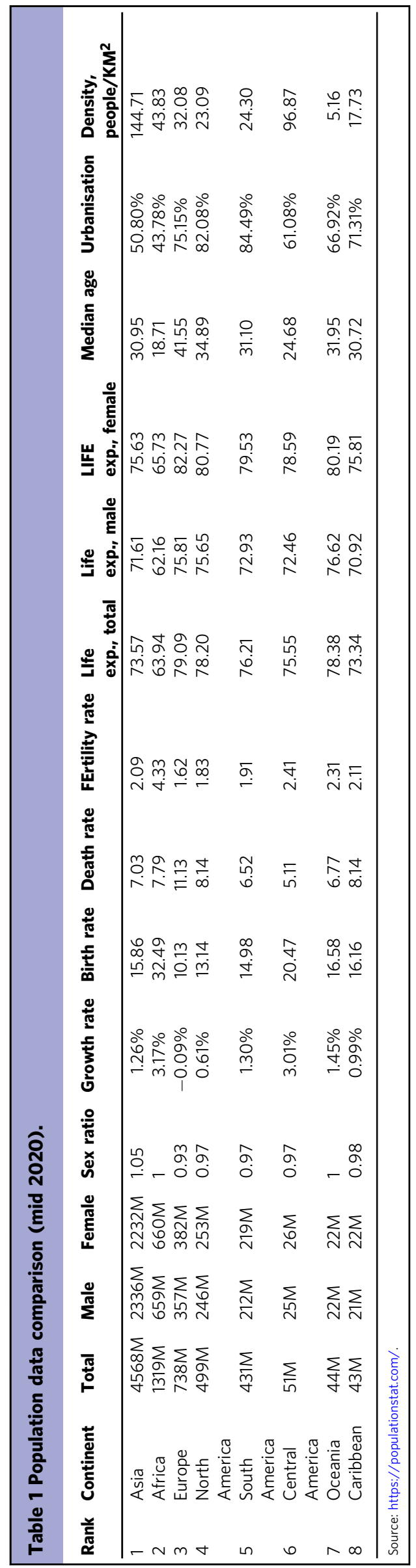


Table 2 Population data continent wise (mid 2020).

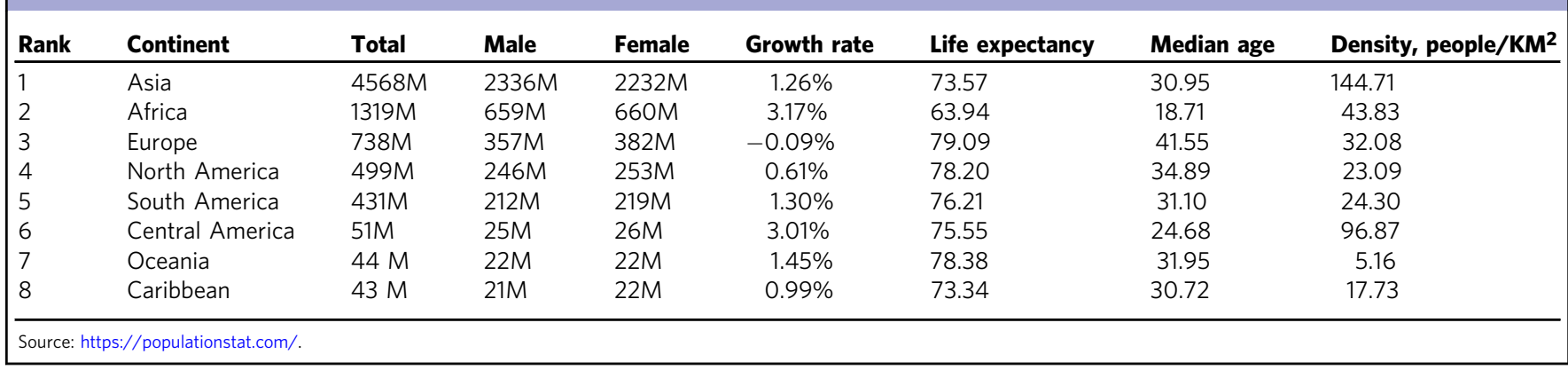

Table 3 World Population history from 1960-2020.

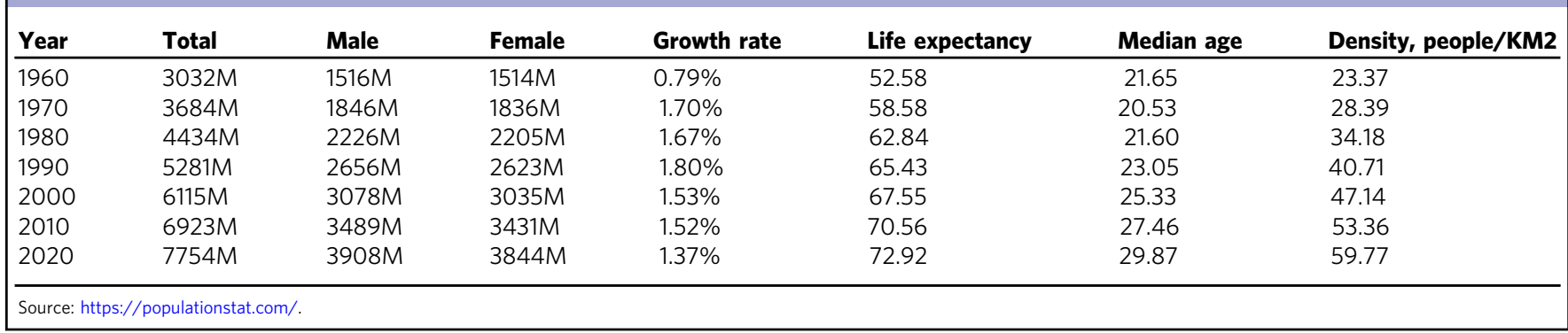

Table 4 World population projection from 2021-2050.

\begin{tabular}{llllllll} 
Year & Total & Male & Female & Growth rate & Life expectancy & Median age & Density, people/KM2 \\
\hline 2021 & $7833 \mathrm{M}$ & $3948 \mathrm{M}$ & $3883 \mathrm{M}$ & $1.33 \%$ & 73.06 & 30.10 & 60.38 \\
2030 & $8501 \mathrm{M}$ & $4280 \mathrm{M}$ & $4218 \mathrm{M}$ & $1.02 \%$ & 74.37 & 31.97 & 65.53 \\
2040 & $9141 \mathrm{M}$ & $4594 \mathrm{M}$ & $4543 \mathrm{M}$ & $0.74 \%$ & 75.65 & 33.58 & 70.46 \\
2050 & $9673 \mathrm{M}$ & $4856 \mathrm{M}$ & $4814 \mathrm{M}$ & $0.52 \%$ & 76.80 & 35.14 & 74.56 \\
\hline \multicolumn{2}{l}{ Source: https://populationstat.com/. }
\end{tabular}

transportation, air travel takes few hours to reach from one continent to another, and before identifying the infection, an infected individual can reach another part of the world while acting as a carrier of viruses and diseases. In future, the tendency of the outbreak will be more with an increase in the human population's and travelling, helping the infections and viruses to spread quickly. Allen et al. (2008) mentioned that more the increase in people's connectivity, more the risk of infection will rise, even in remote locations across the globe.

The number of people interacting with animals and their ecosystem's rise in international trade and travel and adaption of different species with genetic up-gradation changes how human beings deal with pandemics. According to an estimate, more than 300 new viruses, bacteria, or other infectious diseases have emerged in the last few decades. While seeing the population growth and continues occurring of events, health authorities worldwide are working to strengthen public health organisations. The focus diverted to giving more resources to protect people, with new researchers identifying the ways to understand the infections and virus's fasters, developing the vaccines early in the process, and understanding the complexity of various ecosystems to identify the hotspots of emerging diseases.
Preparation and prevention for epidemics and pandemic. Humanity has faced several epidemics, pandemics and continually working to understand the behaviour and patterns for prevention and containment as a part of preparedness, required by all national and international agencies altogether (Xia et al., 2012). An endemic or epidemic is required to be investigated with following aspects while modifying the sequences depending upon factors like the type of infection or virus, population size, geological and environmental conditions to minimise the chances of converting in the pandemic.

\section{Authorities.}

- Registration of infected individuals

- Improvisation in hygienic conditions of people

- Measures preventing infection outbreak into large populations

- Prophylactic fumigation

- Sealing the borders

- Science communication

- Health hygiene education

- Vaccination for all 


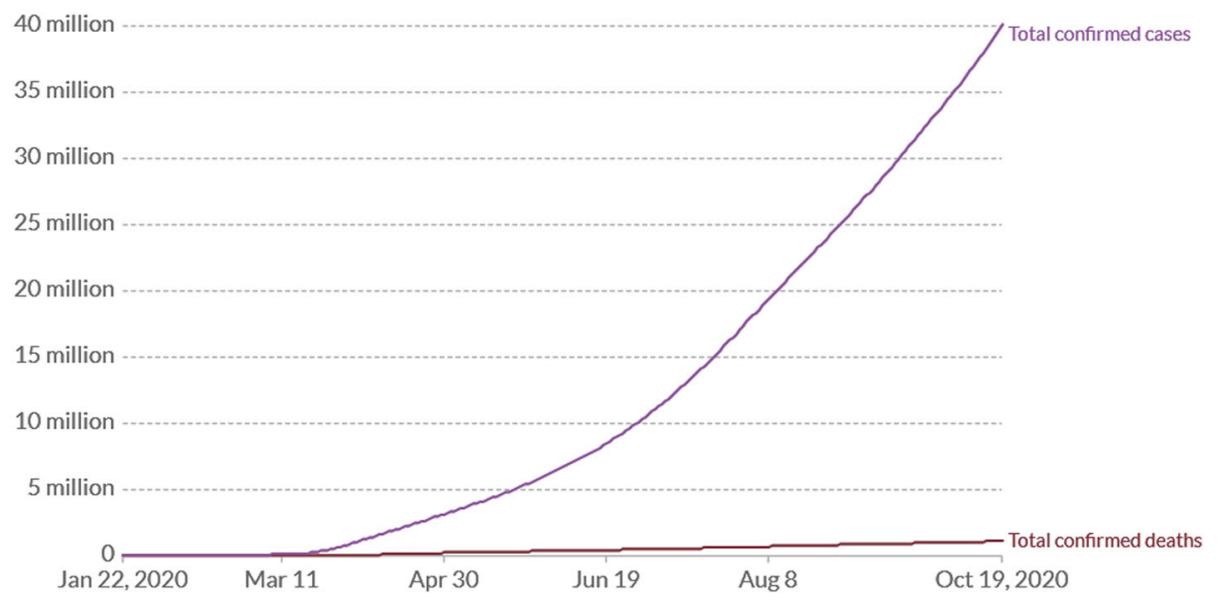

Source: European CDC - Situation Update Worldwide - Last updated 19 October, 10:35 (London time) C CC BY

(a)

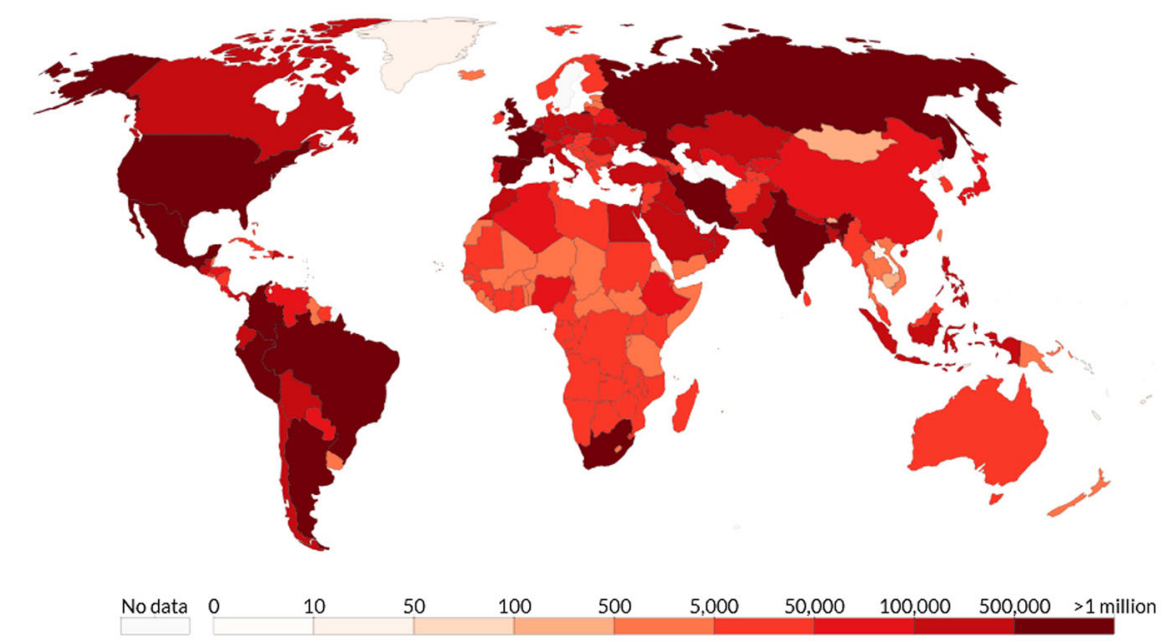

Source: European CDC - Situation Update Worldwide - Last updated 19 October, 10:35 (London time)

(b)

Fig. 2 Graph and Map showing the confirmed COVID-19 cases and deaths across the world till 19 October 2020. : This figure is covered by the Creative Commons Attribution 4.0 International License as mentioned on Source: https://ourworldindata.org/coronavirus-data.

II. Scientists and researchers.

- Surveillance and detection of a problem

- Confirming the existence of the outbreak

- Identifying cases and Isolation

- Comparing the pre-epidemic records

- Epidemiological studies

- Listing the cases and epidemic curve

- Hypothesis and comparative studies

- Legion study to review collect data

- Observations based on a review

- Environmental and cultural surveys

- Assess inter-connections

- Developing control measures and sharing findings

Further, during and post-outbreak, constructive measures are required to minimise the adaptability or mutation by infectious disease.

- Antimicrobial confrontation is of significant concern requiring the development of high-end laboratory facilities with antimicrobial susceptibility tests (AST), collaborating with national and international agencies like WHO.
- Implementing biosafety or biosecurity facilities to all regional and national laboratories with high-security to minimise illegal or accidental conditions.

- Continued programmes of data collection, immunisation, and surveillance starting from community level for humans, as well as cattle must conduct to give a check on endemic and epidemic.

- Collected data must be shared with governing agencies, regional and national laboratories for further assessment with changes in environmental conditions and act as "key for preparedness" for any endemic or epidemic before its outbreak in other parts of the globe.

- Continue improvisation in clean water, sanitation and hygienic facilities to improve community health conditions.

- Scientific communication, the most critical factor could make a win or lose situation. People participate with clear and authentic understanding of health hygiene to prepare and prevent any endemic or epidemic.

This paper deals with aspects of science communication while explaining the importance of science for society in the present and future epidemic and pandemic conditions. 
Health care system and scientific communication. The need for science communication for sustainable development in society requires clear and effective communication to increase the scientific understanding and temperament of common masses with factual and authenticate information without any language barriers. Scientific communication encompasses technical writing from research communication to communication for common masses with playing an extensive role in education and research, in government agencies and the industrial sector (Matta and Kumar, 2017). But, the complexity of research outcomes and lack of interpretation in common terminology, creating a significant gap in understanding of the latest scientific developments for society.

With the dynamic advances in science and technology, the world is accelerating the healthcare system's complexity, making it more complicated with tests and experiments. These developments and advancements in the health care sector with the key stakeholders (medical agencies, health centres, and pharmaceutical industries) are facing challenges to communicate benefits to the patients. Example: Patients visiting a healthcare centre, doctors try to communicate in a simplified way concerning issues and medicines, most notably the precautions, but lack of technical understanding and many times language barriers of patients make it a complicated situation.

Significantly it is a challenge and an opportunity-driven by the world with variation in levels of complexity in the healthcare system. With global accessibility, patients search every information on internet sources before visiting any physician or health care centre and generally visit to confirm whether searched information is right or wrong. All digital platforms are interconnected, and if the information shared on one platform, in seconds, can be seen on other platforms in any part of the world (Zhu et al., 2019). In the health care system, the digital world is full of blogs with home remedies, health care tips and even medicines of concerning issues, but authenticity is always a question, particularly during sharing unauthentic information, leading to misguiding the end-users of information. Research and development is a continuous process in medical science with a focus driven for the good health of every individual in society, but they are not even aware of the same. Healthcare centres with robust communication policies and patients with a properly scientific understanding equally make a healthy outcome, primarily regional or global health disasters.

Steps for effective science communication. Scientific communication is essential for scientific findings to communicate with society and other branches of sciences beyond the barriers of conceptual framework and language. Even an economist or policy planner must understand the need for research findings to implement for society, especially during health emergencies or natural and human-made disasters. According to Suzanne Spitzer, for positive behaviour change and to increase scientific temperament, we must use systematic and academically rigorous scientific approaches with creative and interactive steps of science communication tools (Spitzer, 2017).

1. Team building from interdisciplinary sciences. Earth is full of diversity from environmental to zoogeographical, regional to linguistic and level of education to poverty. The team of experts from various disciplines and agencies like industries, academia or research institutes for policymaking or to implement management plans, can solve better complexity of concerning problems. Focusing on health care systems, team members can act as planners, as well as communicators to develop and narrate precautions and preventions in simplified language using creative tools of science communication to prepare the communities for the future. For promoting health hygiene practices or preparedness for any endemics or epidemics, approaches of communication are essential for awareness and understanding of safety measures even before the implementation of cure or vaccination to prevent the severity.

2. Communication through science stories. As Frank Sesno stated "exact science must have a story" (Steinhardt, 2017), to simplify the complexity of science writing or narration in the form of the story is an essential tool of science communication to assimilate a message in diversified forms targeting diversified audience. It could be a book, general article, short communication or a sentence which describes the meaning of relevant information to be shared. Social scientists are repetitively praising governments and scientific advisors for promoting the involvement of science communicators in the implementation of policies and management plans. The idea is to create a concise and informative statement, describing important aspects without sacrificing any critical parts. Communication through stories of science must avoid language barriers while involving regional language experts as local communicators to narrate among society. Taking science from laboratory to society does not require publishing in High impact journals or big magazines, but a story with some case studies including graphs, images, or flowchart can contribute to a substantial change.

3. Make the science personal. Why would society care about science? It is the taxpayer who indirectly funds all research and development activities and is the end-user of science. It is challenging for both scientists to communicate and individuals from society to understand the prerequisite of making science personal. Positive change in behaviour of common masses towards science should be in focus involving various communicators at a regional or national level making accessible, the concentrated outcome for maximum utilisation (Matta and Kumar, 2017a). Communications on complex scientific solutions must be communicated and well described while addressing the impact of science on everyday life in society. Making mental models for each age group, connecting with audiences involving local NGOs, teachers, and other local organisations by relating science to everyday lives and culture will help in increasing scientific temperament as preparedness for future. According to Suzanne Spitzer, sustaining dialogues and personal relationships can help communicators avoid any difference with the audience; instead, it can achieve the target while depoliticising issues and make clear that it's nonthreatening and is beneficial for the sustainable development of society (Spitzer, 2017). Example: epidemic Polio as diseases was hard to be accepted by communities in developing countries but using communication practices consciousness for its consequences on the health of children and need of vaccination was conducted involving volunteers from local communities to minimise the linguistic problems made a momentous downfall in the number of Polio affected children globally.

4. Science communication and people's participation. Research conducted is initially hypothetically related to societal problems, many times without any prior survey or discussions in society. For science and society, people's participation with heeding problems requires inputs from common masses, motivating the researchers for searching for solutions to benefit the society directly and indirectly. Communication from both sides is critical, especially in the context of complex scientific problems like endemics and epidemics and approaches like genetic engineering and artificial intelligence. For two-way science communication, specific methods to be implemented depending upon the 
language and age groups for interaction with increase the interests and enthuse to follow the learning process with continuous queries from individuals.

Initially, to educate the society, communicating practical use of the science-based solutions and its impacts on everyday lives, increase the public support and help to identify individuals to communicate further prevailing throughout the society. Example: Literature on environmental pollution and conservation are available for a long time but not followed by many communities. In health hygiene sector, guidelines or do and do not are mentioned based on the scientific outcomes, including the availability of vaccination for many acute diseases. However, due to lack of knowledge and understanding every year, millions of infected individuals are detected. People participation for effective communication, communicators, are required from local communities to share the information without any barrier of language or other making scientific solutions into action.

5. Science communication for creating belief in science. To makebelieve in science, people need to have trust in scientists first. Communicating science to people, need to earn the trust while communicating in their languages with sharing information like details of research groups, working procedures, why the need to understand science, and how science and technology are beneficial. Researchers are generally concerned with aims and objectives, eliminating biasedness, but, in reality, the need for science for society varies from regions to communities to solve complex societal problems. Communicating with people, while sharing the information, must be honest, transparent and focused on community problem with accepted solutions. Role of science communicator is to participate in our communities and country's lives to fill the social contrast with scientific solutions. Communication between science and society makes it imperative to make a two-way inter-disciplinary approach involving members of society, ensuring the science meets humanity's needs with or without region-centric.

\section{Categories of science communication.}

- Digital communication: In the 21 st century, the most prominent tool to share information are digital platforms. Every day new sources of information emerge without authenticity is a critical concern caused by communication from different generations, languages, cultures, and communicators. The target audience for communicating authenticate information in the form of news columns, social media sharing through communicators like journalists and researchers associated with common masses and involved in community services. False information's are provided deliberately to increase the visitors on websites and blogs or for any illegal act, making disbelief of society in science and the communicators. Countering similar activities, critical analysis of available information and mode of communication using digital monitoring systems are required by national and international agencies to put accountability to address the misleading information and the provider. Science communication and communicators are required, containing certain documents and evidence in written or visual modes. Asphyxiating apprehensions of communicators by checks made and if any information comes into the tread, its authenticity checked by respective organisations like WHO, ICMR, and Health Ministries in all respective governments, and if found false, immediately advisories are issued. Sometimes, the reader must have some scientific background, but linguistic barriers must be removed with documenting in regional languages. Example: global concerns for the environment and health hygiene during an epidemic or pandemic like swine flu and COVID19, digital social platforms like www, Facebook, and Twitter, Telegram are playing an extensive role in making the people aware with authenticating do's and don'ts.

- According to a report by the National Academy of Science, USA, it's the communication that counters the infectious diseases while following the concept of "Media Village," which authorities ask to shut themselves off from the outside world while protecting themselves. The scientific community must have their media village to providing authenticate scientific information to the general public to understand the consequences, as there are many sources of information, and it is tough to believe which is correct. With the struggling phases, science communication is growing prominently as a tool to fight global issues like environmental pollution, climate change and health hygiene problems.

- Verbal communication: Practice of verbal communication is the most effective and two-way process involving people's participation in the development of scientific temperament in society. Verbal communication with common masses gives space for sharing facts and required evidence to build strong trust to take the science to its maximum reach. Verbal communication with the availability of various digital platforms for sharing talks recorded narrations and lectures targeting global population without any regional or language barriers with digital translating tools. Contributing to developing surged specifically during global health disasters like COVID19, majorly in the regions where the literacy rate is shallow.

- Visual communication: The human brain is very much acceptable for visual communication, with an estimated $80 \%$ of the information it receives from processing visual mode. Communicating science to individuals without any scientific understanding, lack of education, or with a visual disability, visual communication is a game-changer with pictorial communication in the form of pictures, banners and presentations. Visual communication focuses on distribution and equal participation relatively simple knowledge distribution. Development of clear and appealing messages to communicate with solutions of complex global problems like health hygiene, environmental conservation and during pandemics like COVID19 to reduce the severity of its impact. Example: Water pollution and infectious diseases are the ongoing epidemics, and pandemics touched severity in last 2 decades impacting all continents. Enlisted at 6th goal in SDG to be achieved by 2030 , visual science communication can be a revolutionary step to achieve the target for sustainability.

- Culture communication: Development of ground-level strategies for cultural, community, or region, languagebased effective communication is of substantial concern. Communicate to upsurge the scientific understanding and behavioural change for the integration of science, society, and communication to survive against any disasters like pandemic COVID19. These interdisciplinary approaches involve science communication methods, including the role of literature and Vedic science to help communicators for maximum reach.

COVID19 and science communication. COVID19, a deadly virus is affecting humanity with typical symptoms of cold and fever to severity like Middle East Respiratory Syndrome (MERS) coronavirus and chronic, the acute respiratory syndrome coronavirus. Although the origin is unknown, the hypothesis suggests that SARS-CoV-2 is causing COVID19, arising from the 
cross-species transmission, from an animal reservoir (likely bats) to an intermediary animal host before infecting humans. The very first case detected in Wuhan, China in December 2019 and in January 2020, declared as pandemic on Public Health with Emergency of global concern on 30 January 2020. COVID19 has characteristics to appear suddenly and spread rapidly, could be transmitted through fomites in immediate surroundings of COVID19 positive individual after touching or using. Origin of coronavirus is a mystery and having case fatality rate of 5 to 35 times higher than the influenza virus; still, all the countries are in search of vaccination. Expectancy for airborne transmission is higher in pandemic COVID19 during medical treatments, scientific or industrial procedures, i.e., endotracheal intubation, bronchoscopy, open suctioning, administration of nebulised treatment, manual ventilation before intubation, turning the patient to the prone position, disconnecting the patient from the ventilator, non-invasive positive-pressure ventilation, tracheostomy, and cardiopulmonary resuscitation.

Pandemic COVID19, impacted each human life available on Earth with socioeconomic, behavioural and health aspects. In the last two decades' number of times, researchers raised the concern for the rise in global climate change, pollution, and epidemics gave the warnings for global pandemic though a new respiratory disease. According to the BBC, in 2018, the flue pandemic was just a matter of time; still, millions of unknown or undiscovered viruses hidden in the world (Gorvett, 2018). During 2019, the USA Department of Health and Human Services carried out a pandemic exercise named "Crimson Contagion," assuming a pandemic, beginning from China and spreading throughout the world while predicting 586,000 people die the USA only (Sanger et al., 2020). The outbreak of COVID19 has disastrously impacted many countries with lives and economies while others with people living in warzones, with no availability of primary facility of WASH, soap, or medical. COVID19 is allowed to spread freely will put entire communities in respective geographic regions at risk, and it will be hard to control. Every nation is struggling to slow the outbreak of the COVID19 by precautions and prevention with implementing advisories, sharing authenticate information with societies using tools of science communication, monitoring, treatments, social distancing and lockdowns with stay home, stay safe moto. Unfortunately, COVID19 is not just pandemic for humanity but created devastating social, economic, and political crises, expected to be very hard to overcome. World's largest cities are silent, national and international boundaries are closed, loss of a job, lack of availability of resources like food and medical facilities, making unclear to all when the normality returns. While collecting the data from online sources like WHO and Our World in Data, individual graphs and maps created describing the current COVID19 crisis (See Fig. 2; Fig. 3; Fig. 4; Fig. 5).

Symptoms of COVID19. The virus COVID-19 is a contagious infection transmitted while coming in contact with an infected person (within $1 \mathrm{~m}$ ) having specific respiratory symptoms (infected), risking having mucosae or conjunctiva exposed to infected respiratory droplets. COVID19 virus varies from person to person with symptoms like respiratory disease, cold or fever as mild to moderate indications require Isolation and regular medication if needed. Individuals with medical history (like asthma, diabetes, or heart disease) or over the age of 60 years are at high risk of severity of COVID19. Assessment based on the data collected by WHO and other agencies, it is clear that COVID19 is not any age-bound and ranges from mild symptoms to severe illness and death for confirmed infected individuals. Generally, individuals may get sick with coronavirus for 1 to
14 days before it shows the final symptoms. The standard most symptoms of COVID19 are cough, shortness of breath, fever, tiredness, bluish lips, or face.

Precautions and preventions. Minimising the transmission of COVID19, specific precaution and preventions suggested:

- Authentic information on the severity and impact of COVID19

- Awareness and implementation of health hygiene practices like washing hands and cleaning surroundings

- Immediate implementation and management of WASH practices

- Social and physical distancing

- Use of mask.

- Continues updating the understanding with factual information on health hygiene

WHO has recommended dewdrop and touching base precautions for all medical centres and staff taking care of COVID19 infected persons. With uncertainty on airborne transmission, WHO, US Centers for Diseases Control and Prevention and the European Centre for Disease Prevention and Control continually recommending airborne precautions for aerosol engendering procedures and treatment performed to avoid any risk of infection (WHO, 2020).

- Emphasising the need and use of PPE kits for health care workers, scientists working for vaccination, WASH workers and hand hygiene practices for all.

- Training and workshops organised in different languages by agencies like WHO and UNESCO to communicate Health hygiene practices

Recommending procurement and accessibility of PPE's for all workers, including hygiene supplies and facilities. Communicating importance of regular hand hygiene, breathing etiquette, cleaning and disinfecting surroundings with standard disinfectants, maintaining social distances, lockdown, and avoidance any kind of unprotected contact with individuals, especially with the symptoms of fever or any other kind of respiratory problem.

Science communication during and post-COVID19. The spread of coronavirus or COVID19 has shown the status of preparedness and put the entire human race at risk while giving extreme pressure on the largest economies with severe infectivity and transmissibility of this disease (Tomar and Gupta, 2020). Pandemic COVID19 outbreak impacted on entire health systems and facilities counted best globally. Experiences with COVID19 disastrous impact, society is full of fear in terms of health, finance, education, transportation, job losses and uncertain for the future of humanity. Similar to other incidents, pandemic COVID19 has also boosted the digital world with misinformation and myths regarding risks and future of health crisis, creating panic to every individual, leading to uncertainty and fear. Leading to this, the emotional state of edginess has risen and ambiguity about the present and future threats, people are more fearfully reacting and sharing all the information without knowing the facts on different social platforms. Disturbed and severe impact on the people's outlook for the information they read or see, without further countering or checking its truth, combining with dis-ingenuity and variation, they're utterly petrifying. In these trying times, accurate communication with science communicators can help to overcome our worries. According to a book written by Carl Sagan, in his book "The Demon-Haunted World: Science as a Candle in the Dark," "Science is an attempt, largely successful, 


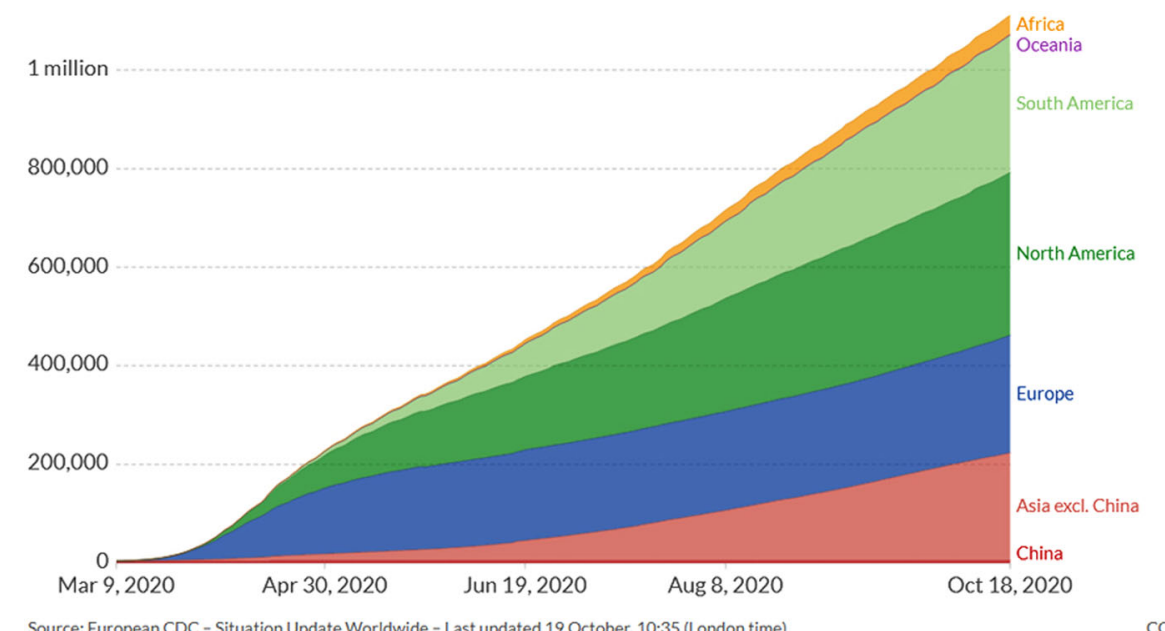

(a)

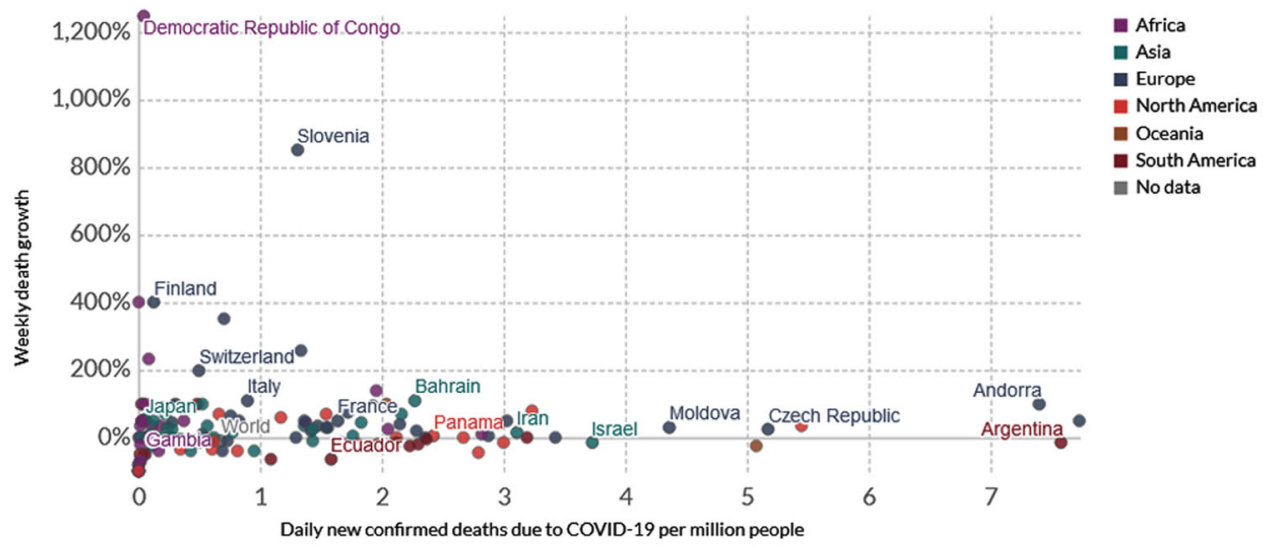

Source: European CDC - Situation Update Worldwide - Last updated 19 October, 10:35 (London time), Our World In Data

$\mathrm{CCBY}$

(b)

Fig. 3 Severity of pandemic COVID19 on different continents. Graphs showing (a) total confirmed deaths (b) weekly death growth rate vs. daily death rate till 19 October 2020. This figure is covered by the Creative Commons Attribution 4.0 International License as mentioned on Source: https:// ourworldindata.org/coronavirus-data.

to understand the world, to get a grip on things, to get a hold of ourselves, to steer a safe course" (Sagan, 1997). It is a proven fact that positive behaviour change with factual information through science communication plays an essential role in society with trusted information from science to society acting as an antidote for negative outlook and helps overcome fear and uncertainty.

Communicating the facts and counter the misleading information's, accurate information on digital platforms in the form of bulletins or updates, organising live press meets and discussions. Despite the lack of access to laboratories, many researchers are working with scientific facts in the form of review articles, short communications and publishing in open access journals. Many institutions are supporting and counting the data and information collected from various trusted sources and statistical websites and directly communicating from scientists as an indispensable ingredient for a better-informed populace. Any science or research is of no use until it directly or indirectly affects the healthy survival of all living forms on Earth. While looking at the scientific outcomes and predictions on COVID19, the actual information shared using science communication tools surely shine some light on the perilous shadows on the fears, disease, and negativity. Commination in times of pandemic, it is essential and necessary to coordinate the policies and actions to address the challenges. Increasing scientific temperament with awareness and understanding of precautions and preventions about coronavirus, the most effective tools is social media, playing a prominent role in motivating people for health hygiene, lockdowns, sharing limitations of governance, developments in scientific communities and severity of coronavirus with the actual number of cases. In contrast, understanding science communication, data sources and message centred approach to be in focus during and post-pandemic COVID19.

Accurate data. the essential resource necessitate for policymaking and implementation of action plans. Various governments and international organisations like WHO, U.N., UNESCO are collecting data for policymaking and preparedness for future epidemics and pandemics. These platforms contributed majorly to respond COVID19. Accurate data in science communication is most important, to understand the size of the society, language, level of education and age group to prepare the literature, design the programme, training of communicators and immediate implementation of the communication process as a response for any epidemic or pandemic. 

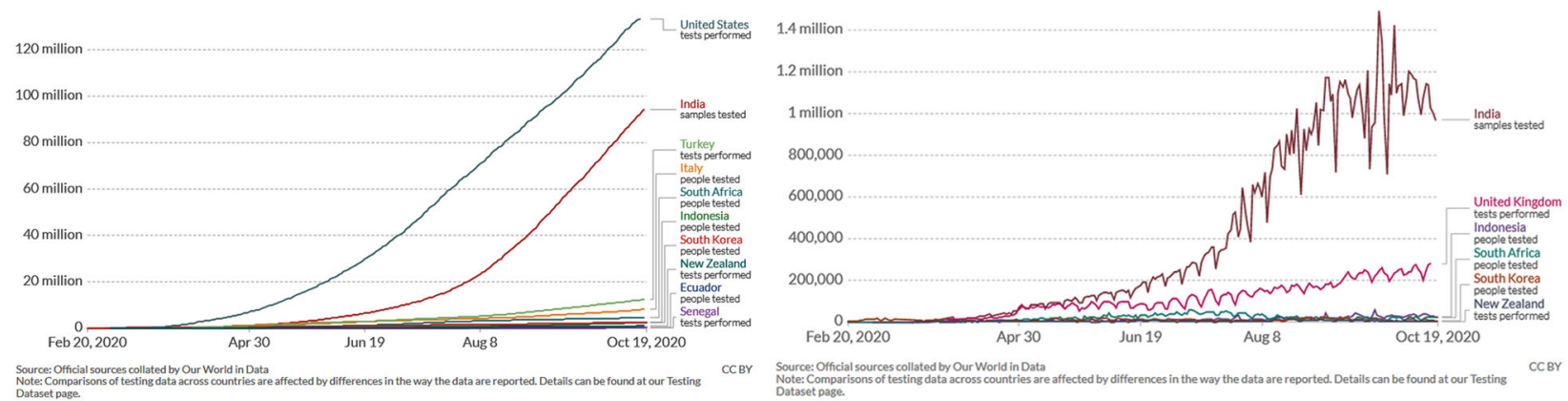

(a)
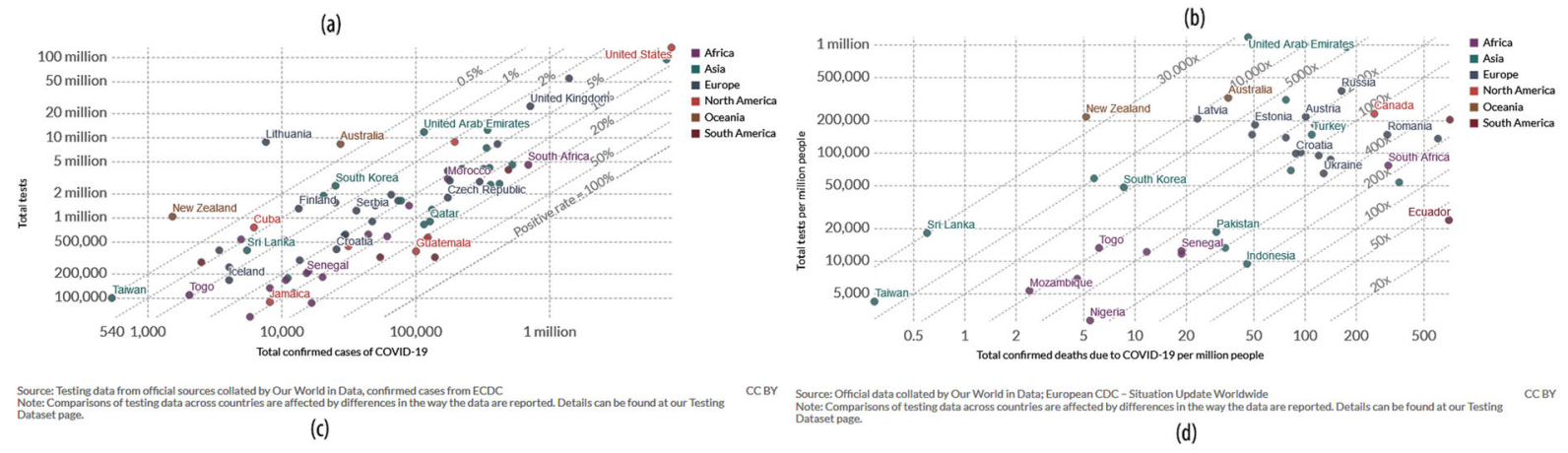

Fig. 4 During the severity of COVID19, the reposnse of government agencies with monitoring and testing to generate factual data for continues upgradation in action plans. Graph showing (a) total number of COVID19 tests conducted (b) Daily COVID19 tests conducted (country Wise) (c) Tests conducted vs. confirmed cases (d). Tests conducted vs. confirmed deaths till 19 October 2020. This figure is covered by the Creative Commons Attribution 4.0 International License as mentioned on Source: https://ourworldindata.org/coronavirus-data.
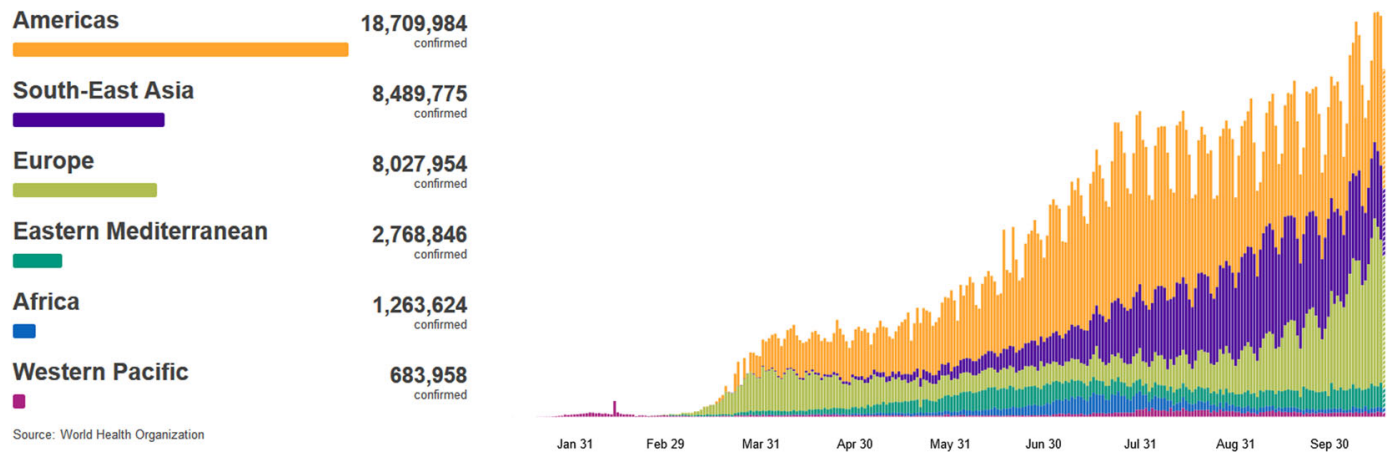

Fig. 5 WHO regions wise case comparison from 11 January to 19 October 2020. Open Source: https://who.sprinklr.com/.

Message centred approach. Approach offers scientists and policymakers to achieve convergence avoiding misinformation or dissymmetry related to epidemics and pandemic. In pandemic COVID19, message centric approach involving medicine, government agencies, science, and economics to build a mutual understanding avoiding any kind of risk of uncertainty while continuing the science communication practices in the right direction for societies to reduce the panic situation. Some of the risk communication factors mentioned in Table 5 (Zhang et al., 2020). According to Zhang et al., (2020), a combined model for Government-Expert-Public Risk Communication comprising of three components of interactive communication: government - public, government-expert and expert-public. In these components, the government is the core decision-maker in all the processes. Other two components involve scientific solutions and societal needs, including social media platforms, to understand the problems of common masses (See Fig. 6).

- Government-public communication: Communication between authorities and community representatives is required regularly for an actual-factual understanding of problems raised due to pandemic COVID19. This component is essentially required during a pandemic, but not implemented in many countries, except India. The country with the second largest population in the world, set the best example government-public communication while appointing government representatives at regional to the national level, sharing contact details on various platforms, continually updating social media accounts of government and addressing of Hon'ble Prime Minister of India soon the COVID19 declared as pandemic while implementing the country lockdown for 21 days.

- Government-expert communication: Government-expert communication is a primary component during epidemic or pandemic like COVID19 for assessing the complications and on-time and quickdecision making. In early stages assessment of the panic situation and future consensus was conducted by experts' for judgements ensuring immediate solution and real possibilities for each potential consequence, to act with rational decisions and minimises the adverse outcomes and maximises the expected benefits (Renn, 2008; Savage, 1951; French, 2012). 


\section{Table 5 The message-cantered approach and its best practices of risk communication (Zhang et al., 2020).}

\section{Best Practices for risk communication}

Infuse risk communication into policy decision

Treat risk communication as a process

Account for the uncertainty inherent in risk

Design risk messages to be culturally sensitive

Acknowledge divers levels of risk tolerance

Involved the public in dialogue about risk

Present risk messages with honesty

Meet risk perception needs by remaining open and accessible to the public

Collaborate and coordinate about risk with credible information sources

\section{Description}

Policies about risk may evolve and be communicated in a variety of ways, Decision making needs to be based on constant risk communication.

Effective risk communication is a dynamic, interactive and adaptive process

Using equivocal messages to convey risk information

Risk communication should fit specific features of the audience

These features include gender, education, age and culture.

People have widely varying capacities to process risk messages, includes scientific and technical understanding of risk

Risk communication dialogues should involve collaboration between the government, industry and citizen that are open, inclusive and deliberative.

Risk communication should be an open, honest and frank process instead of essentially manipulative.

Honest communication is accessible and open as well, which means that the publican receive messages by various channels

Coordination of risk communication strategies requires information sharing and establishing networks of working relationships between groups and agencies

Source: This table is content summary from Sellnow et al., 2009.

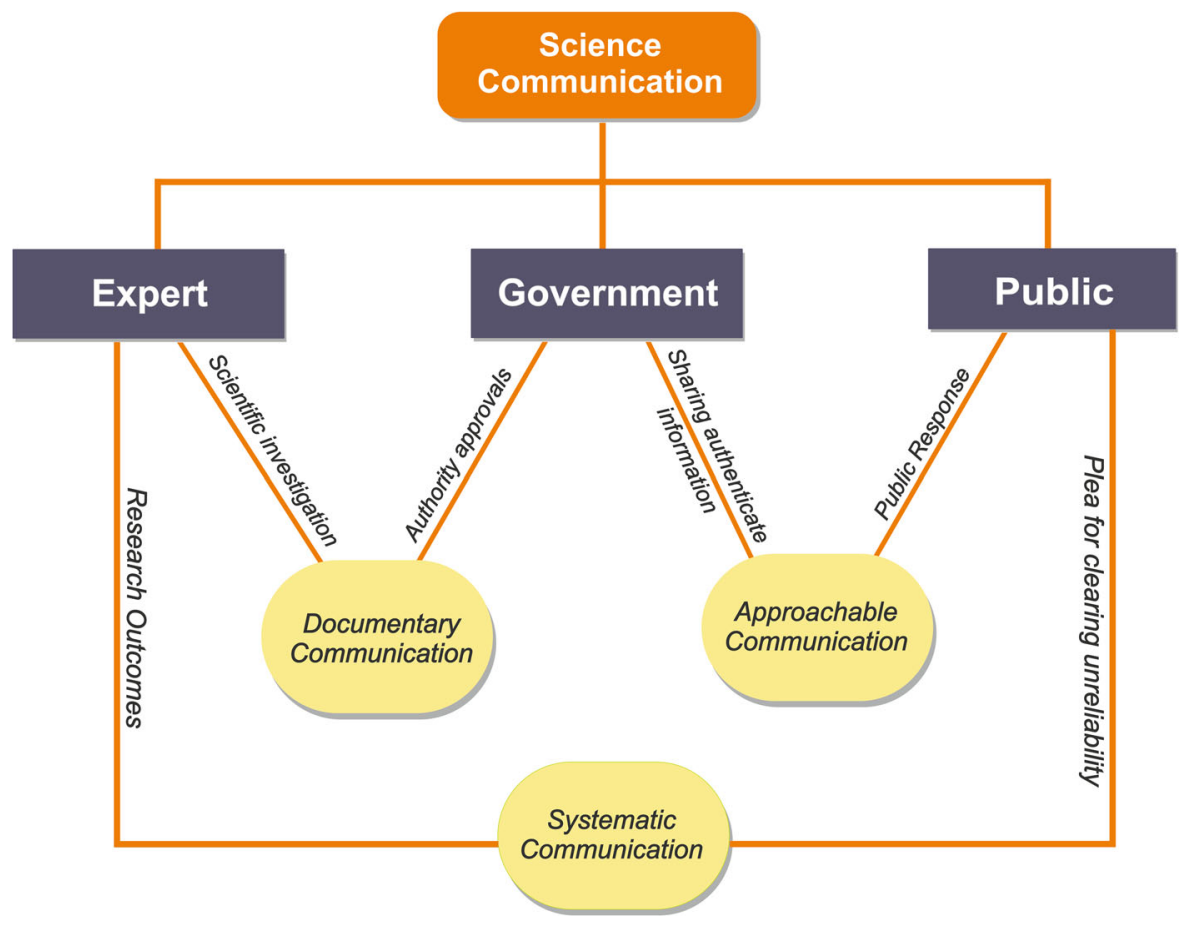

Fig. 6 A model defining science communication between Government, Expert and Public t (Zhang et al., 2020).

Implementing immediate action plan for epidemic COVID19 in January 2020 was taken up by the government agencies, consulting experts including researchers and academicians, using science communication tools while providing guidelines for precautions and prevention of health hygiene. Contributing in the assessment of continues data flow of impact, relating to health, economic and societal risks while sharing findings to the government, publishing as research communications and communicating without any barriers like language or scientific understating for society to aware and recognise the actual situations and act accordingly. During epidemics and pandemics immediate actions, preparedness with continuous monitoring, assessment, and policymaking are essential with involving experts from different field and individuals from society, continues use of tools of science communication is most important (Tucker and Ferson, 2008).

- Expert-public communication: Expert and public communication, the most crucial component with several barriers, especially in developing countries with a different language, geological conditions and environment. Communicating with the global population during a pandemic like COVID19 is a big challenge to communicate and share essential information. Science experts with communicating with people include selecting communicators as volunteers from communities with pieces of training for updated information and scientific knowledge to share with individuals from society with free access to reliable information without any language barrier. The communicator is not just a person, but it has to be the voice of a group of experts to clarify 
the message, transparency, and honesty with scientific facts. It is very much essential to find ways to convey comprehensive information that reflects uncertainty. It empowers the public to follow the guidelines and precautions and to make fact-based decisions about health hygiene like not running or hiding from any health care disease symptoms or like COVID19, instead to fight against the same. Considering the state of complexity in communicating, experts and publication play an imperative to understand who is dealing with whom and which methods to be followed up. Across the globe, there are millions of people who are even fighting with resources needed for survival; while dealing with such complexity, it is the responsibility of the people with science and professional knowledge while including with social understanding about the risk, so experts' responsibility to translate all the information to communicate into explicit and straightforward content which can be easily understood. Interacting with society, science communicators need to understand conditions on the ground level and allow people to express their appeals of finding uncertainty, giving two-way communication and understanding, the science communication can way better, helping and overcoming from the increase in knowledge about the pandemic like COVID19 or any other hazard or disastrous event from some confusing information.

Today in the COVID19 pandemic crisis, organisations like WHO and health ministry's maintaining continuous communication from helping research communities to individuals in society to overcome fears with precise information, guidelines, and precautions to be taken up. As if the communication or science communications have done poorly, it weakens trust; economic and impacts the millions of lives that we see worldwide. Lessons learned from past events like SARS, Middle-East respiratory syndrome (MERS), influenza A (H1N1), and Ebola epidemics, the gap in information and level of confusion from poor communication can trouble more in COVID19 and taking the globe 10-20 years back in terms of life and the economy. Countries fighting with COVID19 and struggling for vaccination must work for humanity with science-based solutions. Altogether, these methodologies build faith and confidence, ensuring that people recognise and understand what they are facing and act responsibly toward their communities while protecting themselves and their families.

\section{Conclusion}

Role of science communication through communicators from the diversity of disciplines need to come forward and communicate the authenticated information to common masses. The need of since communication is to aware and increase the scientific understanding for preventions and precautions responding COVID19 while countering the misleading voices to creating a positive outlook in the society using tools of science communication. Young communicators could play a vital role using technological advancements in communication practices to overcome the barriers like region, language and level of education while minimising direct contact with the masses during epidemics and pandemic. In India, National Council for Science and Technology Communication under the Department of Science and Technology, Govt. of India is continually working on science communication focusing aspects of global concern like health hygiene WASH and environment involving scientists, academicians and individuals to communicate science to society. It's only the forecast of scientists and governance that in the coming world, we are majorly going to need the science communicator, preferably groups of communicators involving individuals from different fields to communicate science, belonging to society.

The world needs more groups of scientists ready to share their expertise into effective communication with no barriers to global concerns and anxieties like pandemic COVID19. Learning from previous epidemics and behaviour of pandemic COVID19, communities can contribute to the reinforcement of stigma while breaking down the barriers and create solutions for the intricate issue of community awareness and enhanced scientific understanding for health hygiene and positive behaviour change. Post passes, leaving the damage created by labelling people who are foreign as dangerous, putting ourselves first and others last, and having a very narrow scope of our sense of responsibility towards society in response to this pandemic. It is not the time to all of "us against them mentality", instead of need to strengthen the communication and cross-collaboration at all levels, to respond to the regional and global crisis. Globally, urgent need to create an environment for shared learning regardless of ideology, with people participation for accurate data collection, communicating science knowledge through communicators among masses and resources to develop vaccines and therapeutics.

COVID19 outbreak has not been confiding to a region or a continent; it's a global health disaster impacting each individual requiring support from each other with following the precautions and preventions for ourselves, neighbours, and the world. Affecting millions and killed over a million individuals with a continuous rise in the number of infected cases even after nine months of its occurrence. The impact during and post COVID19 outbreak can only be checked by communication for improvisation in scientific temperament with social behaviour change, understanding of practical information globally. Further, the information explosion of COVID19 facts and fiction, society must be awarded critically assessed information from science communicators while comparing from sources of national and international agencies. Critical health literacy through the communication of science in the right way making understood as individuals' ability to reflect on complex current health crises and critically assess the information available while being a connecting link for enhancing and encouraging behaviours and mindset that are adequate during a crisis such as the current COVID19 crisis. Awareness for science needs time to grow as in recent times with repetition of endemics and epidemics; time constraints have bounded the understanding of the exact interventions for preparedness and minimising the impact on humanity. With each new challenge, either its pandemic or other global threatening force, various science communication skills are supremely imperative to help with science, the leaders from the government to business technology to community services. Fears of the unknown have no difference between those of the general public, and here science communication through the right communicators may help cut through the noise, share the facts, and boost confidence in common masses on science and governance. It is time to be initiated by fewer people for the betterment of everyone without any discrimination. We're all in this together and fight altogether.

\section{Data availability}

Data sharing not applicable to this article as no datasets were generated or analysed during this study.

Received: 4 May 2020; Accepted: 21 October 2020;

Published online: 25 November 2020

\section{References}

Allen T, Murray KA, Zambrana-Torrelio C, Morse SS, Rondinini C, Tucker WT, Ferson S (2008) Strategies for risk communication evolution, evidence, experience. Ann N Y Acad Sci 1128:9-12

French S (2012) Expert judgment, meta-analysis, and participatory risk analysis Decis Anal 9:119-127 
Gorvett Z (2018) The mystery viruses far worse than flu. BBC Future. https://www. bbc.com/future/article/20181101-the-mystery-viruses-far-worse-than-flu. (14 November 2018). Accessed 13 Oct 2020

Gupta AK (2004) Origin of agriculture and domestication of plants and animals linked to early holocene climate amelioration. Current Science 87(1):54-59

Hanage WP (2017) The next pandemic: on the front lines against humankind's gravest dangers. Emerging Infect Dis 23(12):2123. https://doi.org/10.3201/ eid2312.171137

Jarus $\mathrm{O}$ (2020) 20 of the worst epidemics and pandemics in history. https://www. livescience.com/worst-epidemics-and-pandemics-in-history.html. Accesses 19 Oct 2020

Lindahl JF, Grace D (2015) The consequences of human actions on risks for infectious diseases: a review. Infect Ecol Epidemiol 5:30048. https://doi.org/ 10.3402/iee.v5.30048

Matta G, Kumar A (2017) Role of science and communication in health and hygiene: a case study. ESSENCE Int J Env Conser Rehab 8(2):95-101

Matta G, Kumar A (2017a) Health risk, water hygiene, science and communication. ESSENCE Int J Env Conser Rehab 8(1):179-186

Renn O (2008) Risk governance: coping with uncertainty in a complex world. Earthscan, London, UK

Sagan C (1997) The demon-haunted world: science as a candle in the dark. Ballantine Books, U.S.

Sanger DE, Lipton E, Sullivan E, Crowley M (2020) The Coronavirus Outbreak: Before Virus Outbreak, a Cascade of Warnings Went Unheeded. The New York Times. https://www.nytimes.com/2020/03/19/us/politics/trump-coronavirus-outbreak. html. Accessed 21 July 2020

Savage LJ (1951) The theory of statistical decision. J Am Stat Assoc 46:55-67

Sellnow TL, Ulmer RR, Seeger MW, Littlefield RS (2009) Effective Risk Communication: A Message-Centered Approach; Springer: New York, NY, USA

Spitzer S (2017) Five Principles of Science Communication. Social Science Space. https://www.socialsciencespace.com/2018/04/five-principles-of-sciencecommunication/. Accessed 13 Oct 2020

Steinhardt R (2017) Good Storytelling Moves the Planet Forward. GWTODAY. https://gwtoday.gwu.edu/good-storytelling-moves-planet-forward (10 April 2017). Accessed 13 Oct 2020

The Guardian (2020) Humans: the real threat to life on Earth. https://www. theguardian.com/environment/2013/jun/30/stephen-emmott-ten-billion. Accesses 13 Oct 2020

Tomar A, Gupta N (2020) Prediction for the spread of COVID19 in India and effectiveness of preventive measures. Science of the Total Environment. https://doi.org/10.1016/j.scitotenv.2020.138762

Tucker WT, Ferson S (2008) Strategies for risk communication evolution, evidence, experience. Ann N Y Acad Sci 1128:9-12

United Nations Department of Economic and Social Affairs (UNDESA) (2003) PArtnership and Reproductive Behaviour in Low-fertility Countries. ESA/P/ WP. 177. https://www.un.org/en/development/desa/population/publications/ pdf/fertility/reproduction.pdf. Accessed 13 Oct 2020

United Nations Department of Economic and Social Affairs (UNDESA) (2019) News: growing at a slower pace, world population is expected to reach 9.7 billion in 2050 and could peak at nearly 11 billion around 2100 (17 June 2019). https:// www.un.org/development/desa/en/news/population/world-populationprospects-2019.html Accessed 13 Oct 2020

Wang Z, Bauch Chris T, Bhattacharyya S, d'Onofrio A, Manfredi P, Perc M, Perra N, Salathé M, Zhao D (2016) Statistical physics of vaccination. Phys Rep 664:1-113. https://doi.org/10.1016/j.physrep.2016.10.006
WHO 2020. Modes of transmission of virus causing COVID-19: implications for IPC precaution recommendations. (29 March 2020). https://www.who.int/ news-room/commentaries/detail/modes-of-transmission-of-virus-causingcovid-19-implications-for-ipc-precaution-recommendations. Accessed 21 July 2020

Xia C, Wang L, Sun S, Wang J (2012) An SIR model with infection delay and propagation vector in complex networks. Nonlinear Dyn 69:927-934. https:// doi.org/10.1007/s11071-011-0313-y

Zhang Y, Chen C, Zhu S (2020) Isolation of 2019-nCoV from a stool specimen of a laboratory-confirmed case of the coronavirus disease 2019 (COVID-19)]. China CDC Weekly 2(8):123-124

Zhang Liwei, Li Huijie, Chen Kelin (2020) Effective Risk Communication for Public Health Emergency: Reflection on the COVID-19 (2019-nCoV) Outbreak in Wuhan, China. Healthcare 8(1):64

Zhu P, Wang X, Li S, Guo Y, Wang Z (2019) Investigation of epidemic spreading process on multiplex networks by incorporating fatal properties. Appl Math Comput 359:512-524

\section{Acknowledgements}

The author acknowledges NCSTC, Department of Science and Technology, Govt. of India, New Delhi, India, and Uttarakhand State Council for Science and Technology, Dehradun, India as motivational force to work for science and society through science communication

\section{Competing interests}

The author declares no competing interests.

\section{Additional information}

Correspondence and requests for materials should be addressed to G.M.

Reprints and permission information is available at http://www.nature.com/reprints

Publisher's note Springer Nature remains neutral with regard to jurisdictional claims in published maps and institutional affiliations.

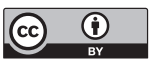

Open Access This article is licensed under a Creative Commons Attribution 4.0 International License, which permits use, sharing, adaptation, distribution and reproduction in any medium or format, as long as you give appropriate credit to the original author(s) and the source, provide a link to the Creative Commons license, and indicate if changes were made. The images or other third party material in this article are included in the article's Creative Commons license, unless indicated otherwise in a credit line to the material. If material is not included in the article's Creative Commons license and your intended use is not permitted by statutory regulation or exceeds the permitted use, you will need to obtain permission directly from the copyright holder. To view a copy of this license, visit http://creativecommons.org/ licenses/by/4.0/

(C) The Author(s) 2020 